Rev. Latinoam. Psicopat. Fund., São Paulo, v. 14, n. 2, p. 329-345, junho 2011

\title{
Os êxtases da Irmã Germana: diferentes interpretações em torno das doenças nervosas no Brasil*
}

Simone S. de Almeida Silva

Cristiana Facchinetti Lorelai Brilhante Kury

\begin{abstract}
Apresenta diferentes concepções em torno dos êxtases de uma beata (Irmã Germana) que viveu em Minas Gerais no século XIX, o parecer do médico Antônio Gonçalves Gomide, seguido do exame de dois cirurgiões e da narrativa do naturalista Auguste de Saint-Hilaire. O objetivo é situar historicamente os textos, investigando as orientações teóricas dos autores e o modo como analisaram os êxtases da beata. A publicação dos documentos pode contribuir para o estudo dos saberes médico-mentais em inícios do século XIX no Brasil.
\end{abstract}

Palavras-chave: Irmã Germana, doenças nervosas, Brasil

* Este artigo é relacionado ao projeto de pesquisa Iluminismo e ciência luso-brasileira: uma semiologia das doenças nervosas no período joanino, desenvolvido por Simone S. de Almeida Silva, doutoranda do Programa de Pós-Graduação da Casa de Oswaldo Cruz-FioCruz (Rio de Janeiro, RJ, Brasil), sob orientação da professora doutora Cristiana Facchinetti e co-orientação da professora doutora Lorelai Kury, a ser concluído em 2011. 
Viveu no interior de Minas Gerais, no início do século XIX. Germana Maria da Purificação passava horas em posição de crucificada sem se mover. Habitava, com permissão de seu confessor, numa capela na serra da Piedade, não muito distante de Ouro Preto, isolada de todos; multidões acorriam ao local para vê-la deitada com os braços estendidos e os pés cruzados, por até 48 horas, sem falar nem comer. Este ritual repetia-se semanalmente. (Schujmaher, S. Dicionário de mulheres do Brasil, 2000, p. 276)

Este é o primeiro parágrafo do verbete "Irmã Germana", presente no Dicionário de mulheres do Brasil, que tem o objetivo de resgatar mulheres que de alguma forma contribuíram para a transformação social do Brasil, mas que permaneceram ocultas da história do país por sua condição feminina.

O recorte do verbete desperta o interesse pela história dessa personagem. Na busca por mais informações, o leitor encontrará relatos variados sobre o estado da Irmã Germana. Provenientes de diversos segmentos sociais, pareceres fornecem informações sobre a personagem e formam uma arena de controvérsias sobre os acontecimentos na Serra da Piedade; são relatos de mulheres que desejavam seguir o modelo de vida da Irmã Germana, relatos de clérigos que avaliaram a sua condição, relatos de médicos e viajantes que estiveram na Serra da Piedade na época em que lá viveu Irmã Germana.

Para este artigo selecionamos dois documentos que oferecem uma boa dimensão dos acontecimentos na Serra da Piedade. São dois escritos que, de fato, apresentam três diferentes narrativas sobre os episódios vivenciados pela Irmã Germana, porque um dos documentos incluiu a publicação de um exame realizado anteriormente.

Tal exame foi realizado pelos cirurgiões Antonio Pedro de Sousa e Manuel Quintão da Silva e constituiu a primeira narrativa sobre as experiências de êxtases da Irmã Germana. Após o exame, eles declararam que os seus êxtases eram de origem sobrenatural, em documento datado de abril de 1814. A segunda narrativa em torno da beata foi o parecer do médico Antônio Gonçalves Gomide (1770-1835), que publicou em 1814 um 
diagnóstico detalhado dos episódios vivenciados por ela, incluindo e comentando a citada declaração dos cirurgiões. A terceira narrativa encontra-se em obra do francês Auguste de Saint-Hilaire (1779-1853), que visitou a Irmã na Serra da Piedade em 1818, publicando posteriormente as informações sobre ela em um de seus diários de viagens, em 1833.

Neste artigo, apresentamos um pouco da história da Irmã Germana e das manifestações experimentadas por ela, através das observações fornecidas pelos personagens que revelaram suas opiniões sobre a beata. Situando historicamente estes personagens, buscamos analisar suas considerações e interpretações sobre o caso para, por fim, pontuar suas orientações teóricas.

A análise desses documentos - aqui republicados - contribui para a compreensão dos saberes médico-mentais em inícios do século XIX, em especial para a compreensão do pensamento científico da época acerca dos êxtases e demais manifestações nervosas. Contudo, antes de analisarmos os relatos sobre a Irmã Germana, contextualizaremos os acontecimentos em torno da história desta personagem.

\section{A Irmã Germana}

Nascida em Minas Gerais, no ano de 1782, Germana Maria da Purificação sofria de contraturas e convulsões que a impossibilitavam de andar. Como outras mulheres conhecidas como beatas, era muito devota e desejava viver recolhida numa vida de oração e penitência. Adaptando-se às condições brasileiras daquele momento em que o acesso aos conventos era limitado, as beatas imitavam a vida conventual mesmo longe de suas muralhas e Germana, seguindo o exemplo de mulheres santas e piedosas que povoavam seu universo místico, seguiu o mesmo caminho (Algranti, 1993, p. 90). ${ }^{1}$

Sendo assim, a beata conseguiu autorização para morar na Serra da Piedade, local que desde a fundação de sua primeira capela fora rodeado de relatos de milagres e experiências místicas, tendo como presença constante a figura dos beatos.

Na Serra da Piedade, ela viveu sob a orientação de seu confessor, o padre José Gonçalves, conhecido e admirado pelos fiéis devido às suas práticas religio-

1. A entrada nos poucos conventos e recolhimentos brasileiros no século XVIII era restrita às mulheres brancas e que possuíssem dotes, condição primária da adesão às casas religiosas (Cf. Algranti, 1993). 
sas (Souza, 1897). Nessa localidade, suas experiências de êxtases, ${ }^{2}$ que a deixavam cada vez mais debilitada, aumentaram a sua fama. Por volta de 1814, mais de mil pessoas venceram o difícil acesso à Serra da Piedade para verificar os fenômenos que Germana manifestava em seu corpo, o que causou tumulto e controvérsias em torno da beata (Gomide, 1814; Saint-Hilaire, 1974[1833]).

A beata tornou-se uma santa no imaginário religioso popular da localidade. Sob a influência de seus "milagres", um grupo de mulheres que expressou seu desejo de ali viverem recolhidas como ela, enviou às autoridades civis e eclesiásticas um requerimento para fundar um abrigo onde pudessem se recolher, como havia feito a Irmã (Jesus, 1818).

Irmã Germana foi "venerada" pelos fiéis, e também foi vista com muita desconfiança por aqueles que, por sua posição teórica, religiosa ou moral, desqualificavam as interpretações de milagre dadas aos fenômenos vivenciados por ela. Tais controvérsias geraram polêmicas na Serra da Piedade, acirradas depois que o bispo de Mariana proibiu a presença da beata na Serra visando, segundo Saint-Hilaire, diminuir as atribuições milagrosas aos fenômenos da beata (Saint-Hilaire, 1974[1833], p. 69). Tal proibição gerou reação por parte dos devotos, contribuindo para as questões em torno da legitimidade da sua condição de "santa", e também da "aura mística" na qual estaria envolta a Serra (Silva, 2003, p. 72).

Os documentos que ora apresentamos são significativos da dimensão das tais embates.

\section{O parecer do médico Antônio Gonçalves Gomide e o exame dos cirurgiões}

O primeiro documento transcrito adiante é um parecer publicado anonimamente pela Imprensa Régia em 1814, escrito por Antônio Gonçalves Gomide.

Filho legítimo de Tomaz Gonçalves Gomide e de Josefina Joaquina de Jesus, ele nasceu em Minas Gerais, onde fez seus estudos preparatórios. Foi enviado por seus pais para Portugal, formando-se em Direito em Coimbra, onde tomou o grau de doutor. Consta também que se formou médico pela Universidade de Edimburgo (Macedo, 1880, p. 83).

Assim, a trajetória do doutor Gomide foi semelhante à de outros brasileiros de famílias abastadas da colônia, que tinham o costume de enviar seus filhos para

2. Conforme o dicionário Raphael Bluteau (1712-1728, p. 398), o êxtase é a suspensão das funções vitais, elevação do espírito abolindo os sentidos. Segundo o autor do dicionário, os êxtases podem ser fruto de causas naturais, como delírio ou alienação mental. 
os estudos na Europa. Segundo as fontes, após seus estudos retornou ao Brasil, em 1792, para trabalhar como professor régio; entre os anos de 1801 e 1806, assumiu as funções administrativas de vereador, capitão de ordenanças e tabelião, em Vila Nova da Rainha, na comarca de Sabará. Foi também deputado em 1823 e senador por Minas Gerais, entre 1826 e 1835, atuando nas comissões de Saúde Pública e Colonização, Civilização e Catequização dos Índios e Instrução Pública.

A Impugnação analítica ${ }^{3}$ de Gomide, conforme mencionado, traz inicialmente o relato dos cirurgiões Antônio Pedro de Sousa e Manuel Quintão da Silva, que examinaram a beata e opinaram favoravelmente ao caráter sobrenatural de suas experiências extáticas, concluindo que não era possível atribuir um juízo médico a um fato que enchia de admiração e respeito. ${ }^{4}$

Doutor Gomide adverte que o objetivo da sua Impugnação é contrariar o exame desses cirurgiões que proclamaram a beata como santa, demonstrando que "uma semiologia razoável nada mais acharia que doença" (Gomide, 1814, p. 1).

É importante registrar que o médico não esteve na Serra da Piedade para examinar a beata, o que gerou comentários, inclusive por parte do padre confessor da irmã Germana, lamentando a ausência do doutor Gomide. É provável que o médico desconsiderasse a importância de uma visita à beata para a realização da sua semiologia, dada a sua leitura laica dos fenômenos e ao fato de que, como afirma em seu parecer, a experiência poderia ser "própria, ou de autoridade" (ibid.,

3. O título completo da obra é: Impugnação analítica do exame feito pelos clínicos Antônio Pedro de Sousa e Manuel Quintão da Silva em uma rapariga que julgaram santa na Capela de Nossa Senhora da Piedade da Serra, próxima à Vila Nova da Rainha do Caeté etc.

4. Ao longo das nossas pesquisas, não foi possível encontrar o material originalmente produzido pelos cirurgiões, bem como outras informações sobre eles.

5. Vale destacar que, nas primeiras décadas do século XIX, foi marcante a disputa entre médicos formados e cirurgiões, os práticos. Em busca de legitimidade e monopólio de atuação, os médicos recusavam as explicações sobrenaturais para as doenças e determinadas práticas que admitiam rituais supersticiosos. Como médico formado, o doutor Gomide defendia a medicina pautada no método da observação e experimentação, para identificação e tratamento das doenças. Suas palavras no parecer, por mais de uma vez, reforçam a ignorância dos cirurgiões para realizar um diagnóstico sobre o caso da Irmã Germana. Observa-se também que o médico se refere aos cirurgiões como clínicos. Como um representante do espírito iluminista, é possível que o doutor Gomide compreendesse o significado da palavra clínico conforme o apresentado na Encyclopédie: aquele que observa o doente em seu leito (Cf. o verbete "Clinique", Encyclopédie, p. 3: 536). Sendo assim, pode-se pensar que o médico quisesse situar o termo 'clínico' como aquele que apenas observava o doente, sem nenhum conhecimento de semiologia ou outra ciência. 
p. 13). O médico condenava justamente a atitude dos cirurgiões que, por se guiarem por "sua prática acima dos autores", não haviam sido capazes de reconhecer "os inúmeros casos semelhantes ao da beata" (ibid., p. 13). Além disso, o pedido feito por Gomide ao físico-mor do Reino para manter o anonimato na publicação de sua Impugnação sugere o temor diante da possível reação dos devotos frente ao seu posicionamento descrente quanto às manifestações da beata.

O fato é que, para o doutor Gomide, os fenômenos da Irmã Germana não passavam do resultado de um estado patológico, frutos de diferentes anomalias da "ação nervosa" (ibid., p. 16). Concluía, deste modo, que seus fenômenos nada tinham de sobrenaturais, mas advinham de uma "catalepsia convulsiva", resultado de uma "doença epiléptica" que afetava os músculos, causando espasmos ou convulsões, deixando a beata com as extremidades contraídas. Ao longo da Impugnação analítica, o médico situa as características da catalepsia, suas espécies e divisões, apresentando precisamente as classificações desta doença oferecidas pelos médicos J. B. Sagar (1702-1778), François Boissiers de Sauvages (1706-1767), Alexander Crichton (1763-1856) e Erasmus Darwin (1731-1802), entre outros. ${ }^{6}$

Erasmus Darwin foi o autor a quem o doutor Gomide recorreu mais vezes na busca de apoio teórico para reafirmar a autoridade de seu conhecimento, frente à suposta ignorância dos cirurgiões. Esse importante médico e naturalista inglês publicou em 1794 a obra Zoonomia or The laws of organic life. O doutor Gomide cita casos clínicos mencionados na Zoonomia de Darwin, bem como suas explicações sobre a etiologia, a fisiologia e os sintomas da catalepsia. No caso da beata, apoiando-se no texto de E. Darwin, conclui que os movimentos convulsivos eram resultado dos esforços contra as dores e adverte que era necessário providenciar a cura para a beata, pois caso contrário ela poderia ficar louca ou morrer durante os acessos de catalepsia.

Ainda, a estratégia de demonstrar sua superioridade científica frente aos cirurgiões é reforçada por sua recomendação, ao que parece irônica, de que lessem as obras de cada autor citado para que alçassem o conhecimento verdadeiro da medicina mental antes de cometerem equívocos, como aquele por eles ates-

6. Sobre os médicos citados, ver Hosack, David. A system of pratical nosology to which is prefixed a synopsis of the systems de Sauvages, Linneus, Vogel, Sagar, Macbridge, Cullen, Darwin, Crichton, Pinel Par, Swediaur, Young, and Good with references to the best authors on each diseases. 2a. ed. Nova Iorque: Van Winkle, 1821. Disponível em: http:// books.google.com/ books?id=fuxlAAAAIAAJ\&pg=PA300\&dq=Sagar+catalepsia\&ei=N_6ZT fnFApyuyQTOjt31Bw\&hl=pt-BR\&cd=1\#v=onepage\&q\&f=false. Acesso em: 20 mar. 2010. 
tado. O médico apresenta ao final da Impugnação analítica uma lista com nome de livros, anais e periódicos científicos, dedicados ao tema da catalepsia. ${ }^{7}$

Seus argumentos em defesa do caráter patológico das manifestações da beata são cuidadosamente construídos a fim de mostrar a legitimidade dos médicos que, com autoridade e conhecimento baseados na observação e experimentação, estariam mais preparados para identificar os sintomas das doenças.

Enfim, a maneira como o texto foi construído, bem como os elementos presentes no parecer do médico nos mostram que o doutor Gomide compreendia a medicina com base no conhecimento científico e na ciência experimental, em oposição à medicina praticada pelos cirurgiões e curandeiros, para ele desqualificada.

A leitura de Impugnação analítica mostra que a intenção do médico, para além de sua crítica pontual ao problema da Irmã Germana, era a de se situar como representante das ideias mais atuais na época, bem como demonstrar-se a par dos estudos mais recentes da medicina europeia.

No que se refere às concepções milagrosas em torno da beata, por parte dos cirurgiões e populares, tem-se a impressão, num primeiro momento, de que o médico recusava totalmente quaisquer ideias religiosas. No entanto, um olhar mais atento revela que ele se situa contra as manifestações de religiosidade dos populares que não concebiam Deus de uma maneira mais racional, ancorada no pensamento ilustrado e nos moldes da religião institucionalizada. De acordo com suas palavras, "é ter uma ideia mais digna de Deus concebê-lo como causa das causas, do que recorrer incessantemente a ele para dar razão de efeitos extraordinários e triviais" (Gomide, 1814, p. 12).

A reação do doutor Gomide contra as manifestações populares em torno da Irmã Germana estava em sintonia com as ações do bispo de Mariana, que buscava limitar as devoções populares em torno da beata. Neste sentido, é possível observar, no início do século XIX, os primeiros sinais de uma postura da Igreja Católica de "saneamento" das manifestações religiosas populares, que culminaria posteriormente no processo de romanização do catolicismo brasileiro (Silva, 2003, p. 72). Vale ressaltar que a Impugnação analítica é um dos primeiros tex-

7. É interessante observar que tal lista é quase idêntica às listas bibliográficas sobre a mesma enfermidade presentes nas obras de pelo menos dois médicos do século XVIII, o inglês W. Rowley (1788) e o alemão Rudolph A. Vogel (1772). Este procedimento do doutor Gomide indica a sua atitude ilustrada, tanto no fato de se mostrar sintonizado com as modernas leituras acerca da catalepsia quanto no de incorporar trechos de autores que o antecederam, nem sempre os citando diretamente. 
tos publicados no Brasil a apresentar o ponto de vista da medicina mental científica moderna, entre os séculos XVIII e XIX. Como o autor inseriu em sua publicação o parecer dos cirurgiões que visitaram a beata, temos aqui um documento que contribui enormemente para a análise das diferentes maneiras de se interpretar um mesmo episódio, abrindo-nos perspectivas para as diferentes linguagens do campo científico daquele período.

Quanto aos cirurgiões Antonio Pedro de Sousa e Manuel Quintão da Silva, sabe-se que eles atuavam nos arredores de Caeté, mas pesquisas realizadas não nos permitiram levantar quaisquer outras informações sobre esses práticos. É importante ressaltar que, por razões diversas, nesse período Minas Gerais tinha poucos médicos, e contava então com a presença de boticários, cirurgiões e outros práticos para atender as demandas dos doentes.

\section{A presença de Auguste de Saint-Hilaire no Brasil e seu olhar sobre a Irmã Germana}

O naturalista publicou várias obras sobre cada região visitada por ele no Brasil, quando aqui esteve entre os anos de 1816 e 1822. A sua visita à Serra da Piedade e à Irmã Germana ocorreu em 1818 e foi descrita em Voyage dans le district des diamans et sur le littoral du Brésil (Viagem pelo distrito dos diamantes e litoral do Brasil), cuja primeira edição francesa é de 1833 , em dois volumes. ${ }^{8} \mathrm{O}$ trecho sobre Germana é transcrito adiante. ${ }^{9}$

Auguste de Saint-Hilaire, filho de família nobre de Orleans, dedicou-se à botânica, atuou como naturalista e publicou artigos sobre a flora europeia, antes de partir para a expedição no Brasil. Saint-Hilaire frequentava o Museu de História Natural de Paris, e mantinha contatos com outros naturalistas, como Antoine-Laurent de Jussieu e o explorador alemão Alexander Von Humboldt (1769-1859). Também estava ligado a Joseph-Philippe-François Deleuze, ajudante-naturalista e depois bibliotecário do Museu, envolvido com as ideias mesmeristas, o que tal-

8. Voyage dans le district des diamans... foi publicado como a segunda parte de Voyages dans l'intérior du Brésil. Na edição de 1833 (Paris: Gide), o trecho sobre Germana se encontra no volume 1, p. 142-149.

9. A presente transcrição foi retirada da tradução brasileira de 1941 (Viagens pelo distrito dos diamantes e litoral do Brasil. São Paulo: Companhia Editora Nacional, 1941, p. 117-123). Neste artigo, usamos como referência a edição brasileira de 1974, idêntica à de 1941 . 
vez explique a influência daquele movimento sobre o naturalista (Kury, 2004a, p. 3), conforme é possível verificar no seu texto sobre a Irmã Germana. ${ }^{10}$

O naturalista chegou ao Brasil com a missão de recolher informações e exemplares para o Museu de História Natural de Paris. Seguia as orientações científicas recomendadas aos viajantes-naturalistas: "pesquisa in loco, especialização, capacidade de produzir informações balizadas, publicação dos resultados" (ibid., p. 5).

Essas orientações adotadas pelo naturalista francês também se adequavam às práticas científicas seguidas pelos intelectuais luso-brasileiros. No momento da viagem do naturalista para o Brasil, em 1816, aqueles experimentavam um processo de conversão, ocorrido no sentido de uma busca de aproximação do funcionamento dos sistemas coloniais hegemônicos, francês e inglês, que tinham o conhecimento científico integrados a suas práticas administrativas e políticas de dominação (Kury, 2004b, p. 111).

Além desse movimento de conversão às práticas científicas hegemônicas, o Brasil acabava de experimentar o processo de transferência da Corte, seguido do assentamento de instituições como a Real Biblioteca (1810), a Imprensa Régia (1808), o Museu de História Natural (1818) e outros.

Desde a segunda metade do século XVIII, a administração portuguesa, apoiando ações que visavam o desenvolvimento das ciências, empreendia expedições científicas objetivando a exploração dos recursos naturais do Império. A partir do fim das guerras napoleônicas, muitos estrangeiros puderam conhecer e explorar o território e a cultura da América portuguesa, tarefa assumida por naturalistas, astrônomos, engenheiros, médicos e outros pesquisadores formados nas instituições europeias (Domingues, 2001; Dias, 1968, Dantes, 1988).

No Brasil, Saint-Hilaire procedeu de maneira aconselhada por seus superiores, mas também teve a possibilidade de se guiar sozinho pelas regiões, decidindo o destino de suas paragens e pesquisas. Seu trabalho de coleta e descrição foi minucioso. Ele acreditava que sua viagem era mais do que coletar plantas; argumentava que sua missão era de caráter utilitário e ponderava sobre a sua atuação em prol da ciência, acima dos interesses mais diretos da população das regiões visitadas. Analisando sua vida como naturalista, afirmou: "talvez eu não tenha sido inútil aos meus semelhantes, quando submeti aos princípios rigorosos da ciência

10. As práticas mesmeristas se baseavam na teoria de Franz A. Mesmer, que acreditava ser possível restaurar a saúde através do restabelecimento do livre trânsito do fluido magnético no corpo. Mesmer promovia sessões terapêuticas nas quais os pacientes eram submetidos a "passes" e entravam em transe. Essas práticas também ficaram conhecidas como magnetismo animal (Darnton, 1998, p. 14). 
o exame das plantas que os brasileiros empregam para o alívio de seus males" (Saint-Hilaire, 1840, p. 22).

Seu texto fez uma descrição minuciosa das paisagens, vegetação e episódios presenciados no Brasil e retrataram de forma ao mesmo tempo global e detalhada a realidade observada. Desta maneira, não há dúvidas do sucesso de suas descrições de viagens para a historiografia brasileira.

A presença do viajante na Serra da Piedade ocorreu provavelmente entre 1816 e 1818. Saint-Hilaire, circulando na região, afirma que, em razão do adoecimento de um de seus ajudantes da expedição, foi obrigado a permanecer ao pé da Serra por alguns dias. Diante dessa parada, diz ter sido possível percorrer a Serra da Piedade, que no seu ponto mais alto possuía uma "pequena plataforma, de onde se descobre o mais extenso panorama que me foi dado a apreciar depois que me acho na Província de Minas Gerais" (Saint-Hilaire, 1974[1833], p. 67).

Foi na Serra da Piedade que Saint-Hilaire afirma ter conhecido Irmã Germana, embora ele já houvesse escutado comentários acerca da beata, talvez por conta das polêmicas geradas, em torno dela, entre os cirurgiões e o doutor Gomide. No seu relato, o naturalista apresenta a beata narrando os acontecimentos em torno dela, com base nas histórias recolhidas ao longo de suas andanças pela Serra. Como um naturalista que percorre territórios colhendo material e fazendo análise e descrição, o viajante recolheu alguns depoimentos sobre a beata. Conversou com o padre José Gonçalves, confessor e diretor espiritual da Irmã Germana e com os populares que visitavam o local; obteve informações sobre a beata através da irmã que a acompanhava, e falou com a própria Irmã Germana. Após a visita, registrou suas informações relatando suas impressões sobre a beata; no entanto, diferentemente dos cirurgiões e do médico, não teve a intenção de realizar um parecer sobre ela.

De acordo com suas informações, depois de sua transferência para a Serra da Piedade, Irmã Germana tornou-se mais debilitada, não andava e comia pouco. Descreveu então com detalhes as alterações corporais apresentadas pela Irmã Germana durante os êxtases. Dando continuidade à sua narrativa, o naturalista destaca também as proibições do bispo de Mariana de celebração de missas no alto da Serra da Piedade e os acontecimentos seguintes; quando obrigada a deixar a localidade, optou pelo recolhimento na casa do seu diretor espiritual.

O naturalista narrou ainda as atitudes dos devotos que, inconformados com a proibição de cultos na Serra da Piedade, solicitavam ao rei intervenção contra a atitude do bispado de Mariana. Após relatar o desfecho do episódio de afastamento da irmã Germana, ressaltando que o pedido ao rei fora atendido, o naturalista descreve um pouco mais os êxtases da beata, destacando algumas variações e relatando as experiências realizadas sobre ela durante as manifestações extáticas.

Rev. Latinoam. Psicopat. Fund., São Paulo, v. 14, n. 2, p. 329-345, junho 2011 
Saint-Hilaire não deixa de registrar também em seu diário de viagem as impressões dos cirurgiões que escreveram sobre o caso da beata e também do parecer do doutor Gomide. E através das informações recolhidas, com a postura desejada de cientista de sua época, o naturalista coloca em prática seus objetivos; a descrição do episódio, da realidade observada, situando-se em seu diário, ao lado da ciência iluminada do nosso doutor Gomide: para ele a beata "fora atacada (...) de afecções histéricas acompanhadas de convulsões violentas. Fizeram-na exorcismar; empregaram-se remédios inteiramente contrários ao seu estado e o mal agravou-se" (Saint-Hilaire, 1974[1833], p. 68).

Submetendo o caso em torno da beata à observação, ele retrata os episódios, oferecendo ao leitor as diversas percepções daqueles que se pronunciaram sobre os acontecimentos na Serra da Piedade.

A descrição da visita de Saint-Hilaire à Serra da Piedade é uma fonte rica de informações sobre a Irmã Germana e também sobre a percepção dos médicos, cirurgiões, religiosos e populares em torno do fenômeno religioso e/ou patológico.

\section{O texto dos cirurgiões, do médico e do naturalista:} uma arena de controvérsias

Apesar de tratarem do mesmo episódio, os êxtases da irmã Germana, os textos são diferentes nas suas propostas. Contudo, as leituras e releituras do parecer médico de Antônio Gonçalves Gomide, do exame dos cirurgiões e do relato de viagem de Auguste de Saint-Hilaire permitiram algumas considerações básicas. Procuramos destacar inicialmente o que exatamente diziam os autores dos textos, e por que foram redigidos. Em seguida buscamos verificar para quem estes autores se dirigiam e como foram produzidas as respectivas obras.

O texto do doutor Gomide, conforme analisado acima, é um parecer médico que foi publicado com o intuito primeiro de contrariar o exame dos cirurgiões que proclamaram a beata como santa, a fim de mostrar que "uma semiologia razoável nada mais acharia que doença" (Gomide, 1814, p. 6). Ou seja, o doutor Gomide desejava afirmar na sua obra que as manifestações da beata eram patológicas, resultado de uma catalepsia.

Mas uma leitura mais atenta do parecer do doutor Gomide mostra também que o médico, ao condenar a atitude dos cirurgiões Antônio Pedro de Sousa e Manuel Quintão da Silva, desejava também condenar as práticas de cura realizadas pelos cirurgiões em geral. Seu discurso se contrapunha a esses práticos que, por não terem se formado na academia, não conheciam as concepções teóricas pre- 
sentes nos escolas médicas. Sua Impugnação analítica, como o próprio nome indica, propunha-se a contestar o exame dos cirurgiões, por meio de uma minuciosa análise teórica, baseando em inúmeros estudos médicos publicados em periódicos e demais produções médicas europeias. O médico produz o seu texto fundamentando seus argumentos com base naquilo em que os cirurgiões eram, aos seus olhos, mais frágeis: o conhecimento teórico das modernas bases científicas da medicina então nascente. O conteúdo da obra foi redigido por meio de uma linguagem bastante formal, carregado de estrangeirismos, cheio de erudição, mostrando a todo o momento que o médico era profundo conhecedor de autores e dos estudos mais atuais da medicina europeia entre os séculos XVIII e XIX. A maneira como a obra do médico foi redigida indica que ele direcionava seu discurso aos cirurgiões, mas não somente a eles. O texto apresenta uma infinidade de referenciais teóricos, que no discurso de Gomide deveriam servir para a consulta dos cirurgiões, mas que na prática serviam muito bem para a exibição do médico, diante da intelectualidade luso-brasileira, como profundo conhecedor das ciências médicas.

Quanto ao material dos cirurgiões, percebe-se que eles realizaram apenas uma narrativa do que foi observado durante o exame realizado na beata. O texto redigido não demonstra que houve preocupação dos autores em analisar os fenômenos, nem mesmo buscar algum tipo de orientação teórica para suas conclusões. Eles simplesmente visitaram a beata e aceitaram a possibilidade de que os episódios fossem de causas sobrenaturais. Os cirurgiões conceberam os êxtases como extraordinários, considerando um milagre que Irmã Germana permanecesse saudável, num estado de jejum absoluto, e declararam que os êxtases eram motivo de admiração e respeito a Deus.

Ao final do exame, acusam de incrédulos aqueles que não acreditavam no estado sobrenatural da beata. As palavras finais no texto dos cirurgiões, cruzadas com as posteriores palavras do doutor Gomide, sugerem a ocorrência de um debate verbal entre os cirurgiões e o médico, antes mesmo da contenda ter chegado aos papéis.

Quanto ao texto do naturalista Auguste de Saint-Hilaire, o que se vê é que seu diário de viagem, quando se propõe a falar sobre a beata, parece apenas querer narrar o episódio, apresentando o local onde ela vivia, as pessoas com quem ela convivia, e os acontecimentos em torno da Irmã. Conforme mencionamos anteriormente, Saint-Hilaire comportava-se como um botânico, o que era de fato, coletando espécies, descrevendo e anotando suas observações a fim de expô-las aos leitores de seu relato. E assim como faziam os naturalistas que por aqui circulavam, ele registrou suas impressões sobre a beata em seu diário, através de uma narrativa que buscava ser bastante fiel e exata, bem ao modo dos naturalis- 
tas quando anotavam dados sobre os costumes dos habitantes das regiões por onde passavam.

Observa-se na interpretação de Saint-Hilaire sobre o caso, que sua redação foi realizada como mais um recorte, mais um exemplar retirado do meio, entre tantos outros realizados por ele nos anos em que esteve no Brasil, e exposto aos seus leitores, o público culto francês e europeu. Sua descrição da beata das Minas Gerais se inscreve num registro quase etnográfico, e pode ser vista como uma análise que buscava ser neutra e objetiva.

É interessante destacar que Saint-Hilaire investiga as experiências da beata através de um exame no local, questionando as pessoas que conviviam com a Irmã Germana, tocando no seu corpo, na tentativa de realizar movimentos em seus braços rígidos, e procurando inclusive realizar experiências baseadas na teoria do magnetismo animal, conforme seus conhecimentos sobre este assunto. Mas seu interesse, longe de adentrar as controvérsias locais, era o de levar para a Europa um mapeamento do país, que abrisse as portas para a compreensão de um mundo que as ciências naturais, pelas mãos de seus cientistas viajantes, começavam a descobrir.

\section{Considerações finais}

Analisando os documentos comentados neste artigo percebe-se que tanto o médico quanto o naturalista viram os episódios da Irmã Germana como observadores externos, descreveram os êxtases da beata numa postura esperada dos homens da ilustração, seguindo o método da observação e a experimentação, pilares do conhecimento científico do período.

A leitura dos documentos possibilita compreender também que tanto o doutor Gomide como Saint-Hilaire partilhavam o mesmo modo de conceber os êxtases da beata, ou seja, como algo resultante de uma manifestação patológica, em oposição às explicações do sobrenatural dadas pelos cirurgiões Antônio Pedro de Sousa e Manuel Quintão da Silva para o caso.

Os cirurgiões expuseram suas ideias com base nas suas noções práticas, muito vinculadas às concepções populares de então. O doutor Gomide optou por um estudo semiológico, com base nos estudos teóricos das "autoridades", conforme suas palavras, que compunham o campo científico da época. Auguste de Saint-Hilaire escolheu um exame in loco, avaliando a pulsação da beata, observando seu estado geral, realizando algumas experiências sobre seu corpo.

Enfim, ainda que o naturalista não tenha exposto claramente suas concepções em defesa do natural para explicar as manifestações da beata, e não tenha 
dialogado com o médico, é possível que suas ideias estivessem sintonizadas com as análises do doutor Gomide, pois ambos se demonstraram comprometidos com o pensamento científico moderno. Os cirurgiões, ao contrário, não deram sinais de comprometimento com um determinado modelo médico-científico.

Finalmente, consideramos importante ressaltar que os documentos são mais que reveladores da história de uma beata que viveu no interior de Minas Gerais. Eles revelam valiosas fontes de informações sobre o percurso da história de medicina no Brasil, especialmente sobre os estudos das doenças nervosas.

\section{Fontes}

Bluteau, R. Vocabulário Português e Latino, vol.1-8, p. 398. Coimbra: 1712-1728. Disponível em: 〈http://www.ieb.usp.br/online/index.asp>. Acesso em: 20 mar. 2011. Diderot, D.; D’Alembert, J. Le R. (ed.). Clinique. Encyclopédie, ou dictionnaire raisonné des sciences, des arts et des métiers. 35 volumes. Paris: Briasson, 1751-1780. University of Chicago: ARTFL Encyclopédie Project (Winter 2008 Edition), Robert Morrisey (ed), p. 3:356. Disponível em: <http://encyclopedie.uchicago.edu/>. Acesso em: 24 jan. 2011.

Gomide, A.G. Impugnação analítica ao exame feito pelos clínicos Antônio Pedro de Sousa e Manuel Quintão da Silva em uma rapariga que julgaram santa na capela da senhora da Piedade da Serra, próxima à Vila Nova da Rainha do Caeté etc. Rio de Janeiro: Imprensa Régia, 1814.

Jesus, C. da P. de. Pedido para a fundação de um recolhimento. Arquivo Nacional do Rio de Janeiro, Mesa do Desembargo do Paço, caixa 130, pacote 2, doc. 50. 7/7/1818.

Rowley, W. A treatise on female, nervous, hysterical, hypochondriacal, bilious, convulsive diseases, apoplexy and palsy: which thoughts on madness, suicide, etc. London : C. Nourse, E. Newbery, and T. Hookham, 1788, p. 438-439. Disponível em: <http://books.google.com.br/books?id=RsdMzVmjoZQC\&printsec=frontcover\& source=gbs_ge_summary_r\&cad=0\#v=onepage \&q\&f=false>. Acesso em: 2 abr 2011 .

Saint-Hilaire, A. de. Leçons de botanique, comprenant principalement la morphologie végétale... Paris : P.J. Loss, 1840. Disponivel em: <http://books.google. com.br/books?id=JEg-AAAAcAAJ\&printsec $=$ frontcover \&dq $=$ Le $\% \mathrm{C} 3 \%$ A7ons + de + botanique+comprenant+principalement+la+morphologie+v\%C3\%A9g\%C3\%A9tale\&hl =pt-BR\&ei=PZuKTZ_aJImH0QG1xoiEDg\&sa=X\&oi=book_result\&ct=result\& resnum $=3 \& v e d=0 C D M Q 6 A E w A g \# v=$ onepage $\& q \& \mathrm{f}=$ false $>$. Acesso em: 9 mar. 2011. Saint-Hilaire, A. de (1833). Viagem pelo distrito dos diamantes e litoral do Brasil. Belo Horizonte: Itatiaia, 1974. 
Vogel, R.A. Academicae praelectiones de cognoscendis et curandis praecipuis corporis humani affectibus. Gottingae: Vandenhoeck, 1772, p. 473. Disponível em: $<$ http://books.google.com.br/books?id=o-NEAAAAcAAJ\&printsec= frontcover\&source $=\mathrm{gbs} \_g e$ _summary_r $\& \mathrm{cad}=0 \# \mathrm{v}=$ onepage $\& \mathrm{q} \& \mathrm{f}=\mathrm{false}>$. Acesso em: 17 maio 2011.

\section{Referências}

Algranti, L. M. Honradas e devotas: mulheres da colônia, condição feminina nos conventos e recolhimentos do sudeste do Brasil, 1750-1822. Rio de Janeiro: José Olympio, Brasília: EdUNB, 1993.

Dantes, M. A. M. Fases da implantação da ciência no Brasil. Quipu, São Paulo, v. 5, n. 2, p. 265-275, mai./ago. 1988.

Darnton, R. O lado oculto da revolução: Mesmer e o final do Iluminismo na França. São Paulo: Companhia das Letras, 1998. p. 14.

DiAs, M. O. S. Aspectos da ilustração no Brasil. Revista do IHGB, Rio de Janeiro, v. 278 , p. $171,1968$.

Domingues, A. Para um melhor conhecimento dos domínios coloniais: a constituição de redes de informação no império português em final dos setecentos. História, Ciências, Saúde, Manguinhos, Rio de Janeiro, v. 8 (suplemento), p. 823-838, 2001.

KuRY, L.B. Auguste de Saint-Hilaire: viajante exemplar. Revista Intellèctus, Rio de Janeiro, ano 2, n. 1, 2004a. Disponível em: http://www.intellectus.uerj.br/Textos/ Ano2n1/Texto\%20de\%20\%20Lorelai\%20Kury.pdf.> Acesso em: 20 jan. 2011.

. Homens de ciência no Brasil. Historia, ciências e saúde - Manguinhos, Rio de Janeiro, v.11 (suplemento 1), p. 109-29, 2004b.

LeITE, M.L.M. Natureza e naturalistas: profissionalização do cientista. Cadernos IG/ Unicamp, Campinas, v. 5, n. 1, p. 60-76, 1995.

Macedo, J.M. de. Suplemento do ano biográfico. Rio de Janeiro: Tipografia Perseverança, 1880. v. 1.

SILVA, S.S.A. Religião e condição feminina no início do século XIX: controvérsias em torno da Irmã Germana. 2003. 128 p. Dissertação (Mestrado em Ciência da Religião), Departamento de História-ICH, Universidade Federal de Juiz de Fora.

SouzA, J.S. Sítios e personagens. São Paulo: Tipografia Salesiana, 1897.

Schujmaher, S. In: Brazil, É.V. (Org.). Dicionário de mulheres do Brasil: de 1500 até a atualidade. Biográfico e ilustrado. Rio de Janeiro: Jorge Zahar, 2000. 


\section{Resumos} Brazil)

(The ecstasies of Sister Germana: different interpretations of nervous diseases in

The article presents two different views of the ecstasies of a nun (Sister Germana) who lived in Minas Gerais, Brazil, in the nineteenth century. The first perspective was the opinion of Dr. Antônio Gonçalves Gomide, together with an examination by two surgeons; the second was a narrative by the naturalist Auguste de Saint-Hilaire. The goal is to historically situate the texts, investigate the theoretical orientations of the authors and note how they analyzed the woman's moments of ecstasy. The publication of these texts contributed to the study of medical and mental knowledge in the early $19^{\text {th }}$ century in Brazil.

Key words: Sister Germana, nervous diseases, Brazil

(Les extases de la Sœur Germana: les différentes interprétations des maladies nerveuses au Brésil)

Cet article présente les différents aspects de l'extase d'une religieuse (la Sour Germana) qui a vécu dans l'État de Minas Gerais au XIXe siècle, l'avis de son médecin Antonio Gonçalves Gomide, suivi de l'examen de deux chirurgiens et le récit du naturaliste Auguste de Saint-Hilaire. Notre travail est de situer historiquement les textes, d'enquêter sur les orientations théoriques des auteurs et sur la façon dont ils ont analysé l'extase de la sainte. Cet article a comme but de contribuer à l'étude des connaissances médicales et mentales au Brésil au début du XIXe siècle.

Mots clés: Sœur Germana, maladies nerveuses, Brésil

(Los éxtasis de Sor Germana: diferentes interpretaciones acerca de las enfermedades nerviosas en Brasil)

Se presentan diferentes concepciones acerca de los éxtasis de una beata (Sor Germana) que vivió en Minas Gerais en el siglo XIX, la opinión del médico Antônio Gonçalves Gomide, seguido por el examen de dos cirujanos y la narrativa del naturalista Auguste de Saint-Hilaire. El objetivo es situar históricamente los textos, investigando las orientaciones teóricas de los autores y el modo como analizaron los éxtasis de la beata. La publicación de los documentos puede contribuir para el estudio de los saberes médico-mentales en los inicios del siglo XIX en Brasil.

Palabras clave: Hermana Germana, enfermedades nerviosas, Brasil

Citação/Citation: Silva, S.S.de A., FACChInEtTI, C.; KuRY, L.B. Os êxtases de Irmã Germana: diferentes interpretações em torno das doenças nervosas no Brasil. Revista Latinoamericana de Psicopatologia Fundamental, São Paulo, v. 14, n. 2, p. 329-345, jun.2011. 
Editor do artigo/Editor: Prof. Dr. Paulo Dalgalarrondo; Profa. Dra. Ana Maria G. Raimundo Oda

Recebido/Received: 7.4.2011 / 4.7.2011 Aceito/Accepted: 18.5.2011 / 5.18.2011

Copyright: @ 2009 Associação Universitária de Pesquisa em Psicopatologia Fundamental/ University Association for Research in Fundamental Psychopathology. Este é um artigo de livre acesso, que permite uso irrestrito, distribuição e reprodução em qualquer meio, desde que $\mathrm{o}$ autor e a fonte sejam citados/This is an open-access article, which permits unrestricted use, distribution, and reproduction in any medium, provided the original author and source are credited.

Financiamento/Funding: Esta pesquisa é financiada pela Fundação Oswaldo Cruz - Fiocruz/ This research is funded by Oswaldo Cruz Foundation - Fiocruz.

Conflito de interesses/Conflict of interest: As autoras declaram que não há conflito de interesses/The authors declare that has no conflict of interest.

\section{Simone S. de Almeida Silva}

Doutoranda do Programa de Pós-Graduação em História das Ciências e da Saúde da Casa de Oswaldo Cruz/COC, Fundação Oswaldo Cruz/Fiocruz (Rio de Janeiro, RJ, Brasil).

Rua Prof. João Lima, 290 - Santa Paula

Juiz de Fora, MG, Brasil

e-mail: si33santos@yahoo.com.br

\section{Cristiana Facchinetti}

Pesquisadora do departamento de pesquisa e professora do Programa de Pós-Graduação em História das Ciências e da Saúde da Casa de Oswaldo Cruz/COC, Fundação Oswaldo Cruz/Fiocruz (Rio de Janeiro, RJ, Brasil).

Av. Brasil, 4036/400

Rio de Janeiro, RJ, Brasil

e-mail: cfac@coc.fiocruz.br

\section{LORELAi BRILHANTE KURY}

Pesquisadora do departamento de pesquisa e professora do Programa de Pós-Graduação em História das Ciências e da Saúde da Casa de Oswaldo Cruz/COC, Fundação Oswaldo Cruz/Fiocruz (Rio de Janeiro, RJ, Brasil).

Av. Brasil, 4036/404

Rio de Janeiro, RJ, Brasil

e-mail: lolakury@gmail.com 